\title{
Can drug manufacturers change their philosophy?
}

\section{Opinion}

If health-care reform is to become a reality there has to be cost controls. All players must participate including physicians, hospitals, the insurance industry and the drug manufacturers. In my community pharmacy practice, I have gotten asked numerous times by customers with little or no prescription insurance "why are these drugs so damn expensive?" And for many years I have defended the drug manufacturing companies stating to the customer in reply that they have invested millions into the research and development of each and every drug product that is put on the market; that it takes time and money to discover new drugs and to produce the raw materials to make the new drugs to help combat disease states like arthritis, diabetes, and hypertension, and slow the progression of cancer and AIDS. In my career I have seen not only new drug entities, but new drug classifications, new drug delivery systems, new indications, new unlabeled uses, and agents to treat disease states where there was no prior drug treatment available.

Lately however I have had more empathy toward the patient/ customer when asking for $\$ 120.00$ for ten days worth of prescription medication. I believe these drug manufacturers can lower their prices considerably and not take a loss by following these three measures:

a) Elimination of direct-to-consumer advertising of prescription drugs

b) Packaging drugs products more cost-effectively

c) Cease the production of the brand name agent once the patent expires

Let's look at each of these money saving measures. Direct-toconsumer ads are just plain ineffective and unnecessary. Ads for ethical products are often misleading. How does a person know he or she is a candidate for a certain prescription product? Can one self diagnose hypertension, diabetes, high cholesterol, GERD? Is it really overactive bladder or merely a UTI? Is it really acid reflux disease or is that pain gall bladder disease that may go untreated. Diagnosing remains the work of the physician. By all means encourage the public to see their medical providers regularly but do not put ideas in their minds blasting the consumer with print ads and TV and radio spots about drugs that can help a certain medical condition and then list all the unwanted side effects and adverse reactions that almost kill the credibility of the drug product. The disclaimers are longer than the product indication. I doubt if I would want to take a drug to handle my one complaint, if I had to experience headache, dry mouth, constipation, upset stomach, muscle weakness, nausea and other serious side effects. I would hope to have the opportunity to discuss the pros and cons with my physician for each drug that he or she would want me to take. By all means advertise the drug in medical, pharmacy and nursing trade journals. That is one way we health care professionals learn about the newer agents. But weekly magazine and daily newspaper print ads and radio and television commercial spots for prescription drug products? Forget about it!

Secondly, manufacturers are causing each and every retail pharmacist to experience carpel tunnel syndrome what with these safety caps on all prescription bottles. The unit-of-use 30 count
Volume 3 Issue I - 2015

\author{
Bob Spera \\ University of the Sciences in Philadelphia, USA
}

Correspondence: Bob Spera, University of the Sciences in Philadelphia, USA, Tel 6105653383 ,

Email druggist37@verizon.net

Received: September 18, 2015 | Published: December 04, 2015

bottles with safety caps are fine, but I have never dispensed 500 ibuprofen $800 \mathrm{mg}$ on one prescription, so why the safety cap on the manufacturer's bottle. I don't think there are any pharmacists out there under the age of five. If this is an FDA regulation to have safety caps on all manufacturers packaging, then let's lobby to change it. (My feeling is that the FDA should be headed by a pharmacist, but that is the topic for another column.) Drug packaging has to be changed. Unit of use 30's can remain for the very popular drugs with once daily dosing regimens. All other drug products should be packaged in bottles of 100's, 500's and 1000's. Do away with 90 and 120 count idiocy. Most high volume chain pharmacies have automatic counting machines such as Baker Cells and ScriptPro to do the counting. So instead of a large volume pharmacy purchasing 500 sertraline $100 \mathrm{mg}$ tablets and receiving 16 bottles of 30 's, the store can receive one bottle of 500 tablets. Less plastic bottles, less shelf space, less waste! After a drug has been on the market for say three years, stop putting those package inserts glued to the bottles. Every pharmacy has access to the Physicians Desk Reference which is the book of package inserts. Did you ever try to peel a package insert off of a bottle without ripping it? I throw away over 100 package inserts per day. Another waste! If it is an FDA requirement to have a package insert on each bottle, then it is time to change this policy as well.

Lastly, drug manufacturers can save boatloads of money by stopping the production and distribution of all drug products one year after the expiration of its patent. We all know that most $A B$ rated generic versions are made by the companies that marketed the brand name product. Therefore once the generic version is available the drug company should cease making the brand name drug. Most third party prescription plans do not cover brand name drugs if the generic is available. The co-pays are higher. PBM's want the patient to use the generic drug. The manufacturer does not detail the drug anymore. Advertising the drug is over. So just stop making the brand name. There will be no reason for any customer to say "I don't want the generic." The generic will be the only version available. I admit I will miss telling the patient who demands the brand name drug, "The drug receptor sites in your body cannot distinguish the difference between brand and generic versions, so stop throwing your money down the toilet." If I owned my own pharmacy, I would never carry in my inventory a brand name drug when a generic version is available and I would make it a point to inform my customers of this cost-saving 
measure. I realize these ideas are extreme, but they can reduce waste and save money. By implementing these measures and changing their philosophy, drug manufacturers can reduce the prices of their ethical products and pass the savings onto the consumer. In this day where the drug manufacturers have been getting so much bad press with product recalls and drugs being pulled from the market because of side effects, implementing these measures will be well received by the consumer.

\section{Acknowledgements}

None.

\section{Conflict of interest}

Author declares that there is no conflict of interest. 